\title{
INFLUÊNCIA DOS CONTAMINANTES NO RENDIMENTO FERMENTATIVO NA PRODUÇÃO DO BIOETANOL
}

\author{
M. A. GOMES ${ }^{1}$, J. H. S. OLIVEIRA ${ }^{1}$, C. C. AMPARO ${ }^{1}$, R. M. R. G. ALMEIDA ${ }^{1}$ \\ ${ }^{1}$ Universidade Federal de Alagoas, Centro de Tecnologia, Curso de Engenharia Química \\ E-mail: cynha06@hotmail.com
}

\begin{abstract}
RESUMO - As crescentes necessidades de energia da população mundial têm motivado uma corrida sem precedentes à produção de combustíveis renováveis. Nesse contexto, pesquisas vêm sendo realizadas para transformar materiais lignocelulósicos em etanol. Se tratando da matriz lignocelulósica é imprescindível à realização de um pré-tratamento, disponibilizando os açúcares fermentescíveis para produção bioetanol. Durante o processo de pré-tratamento ocorre à geração de inibidores potenciais. $\mathrm{O}$ estudo avaliou o rendimento fermentativo na presença desses contaminantes através de um planejamento experimental fatorial $2^{3}$, com intuito de fornecer subsídios para a otimização do processo de geração do bioetanol. A levedura utilizada no processo fermentativo foi Saccharomyces cerevisiae. Os resultados apresentaram que o ponto mínimo de ácido acético e de furfural, e o ponto máximo de fermento, obteve maior rendimento reacional, comprovando a interferência do ácido acético e do furfural no meio reacional.
\end{abstract}

\section{INTRODUÇÃO}

No Brasil, aproximadamente 350 milhões de toneladas de resíduos lignocelulósicos são gerados ao ano, essa biomassa pode ser encontrada tanto em plantas lenhosas, como em resíduos agrícolas, florestais e até mesmo nos resíduos urbanos e industriais, sendo uma fonte abundante, e como tal, uma matéria-prima atrativa e de menor custo para obtenção de biocombustíveis. (Pereira, 2007; Taherzadeh et al., 2007)

Dentre os materiais disponíveis, os resíduos agrícolas são uma das melhores opções para a produção de etanol. A produção do etanol lignocelulósico, ou etanol de segunda geração, está em constante desenvolvimento, onde a partir da hidrólise da celulose e da hemicelulose os monômeros de açúcar tornam-se disponíveis para a fermentação. Entanto, a liberação dos açúcares monoméricos dessa biomassa para uso em processos fermentativos requer um tratamento adequado tem sido mostrado (Mosier et al. 2005).

Segundo Zhao et al. (2011), durante o pré-tratamento da biomassa para produção de etanol $2 \mathrm{G}$ pode ocorrer liberação de monômeros de açúcares e de substâncias com potencial inibitório na fermentação, como ácido acético e furfural. Todos esses compostos tóxicos afetam a fisiologia da levedura resultando no decréscimo da viabilidade celular, rendimento de etanol e produtividade tal como relatado (Zhang et al. 2013). 
Segundo dados da Renewable Fuels Association (2010), a produção de etanol combustível está em torno de 75 bilhões de litros por ano, e a maior parte deste total, cerca de $95 \%$, é produzida pela fermentação de determinados açúcares pela levedura $S$. cerevisiae, o que reforça a necessidade de estudos sobre a influência de parâmetros que podem interferir no processo fermentativo.

O trabalho avaliou o rendimento fermentativo na presença desses contaminantes através de um planejamento experimental fatorial $2^{3}$, com intuito de fornecer subsídios para a otimização do processo de geração do bioetanol. Para tal, foram inicialmente realizados ensaios de fermentação em meio sintético YPD (Yeast Peptone Dextrose), utilizando a levedura $S$. cerevisiae em níveis máximos e mínimos determinados com base em dados de Wolf (2011); níveis máximos e mínimos de ácido acético determinado com base nos valores obtidos experimentalmente segundo Santos (2014); e furfural com base Taherzadeh et al. (2007). Em seguida, as informações obtidas foram trabalhadas no programa Statistic sendo validadas pelos cálculos realizados conforme Bruns et al. (2007).

\section{MATERIAIS E MÉTODOS}

Para o preparo do inóculo nos ensaios de fermentação utilizou-se o meio de cultura YPD (Yeast Peptone Dextrose), com a seguinte composição: $10 \mathrm{~g} / \mathrm{L}$ de extrato de levedura; $20 \mathrm{~g} / \mathrm{L}$ de glicose; $20 \mathrm{~g} / \mathrm{L}$ de peptona bacteriológica, tendo o $\mathrm{pH}$ ajustado para 5,0.

Como microrganismo utilizou-se a levedura $S$. cerevisiae comercial, na forma de fermento seco. Ao meio de cultura foram adicionados os principais contaminantes gerados no processo de pré-tratamento dos materiais lignocelulósicos: furfural e ácido acético, em diferentes proporções para verificar a partir de qual concentração de qual contaminante influencia no rendimento fermentativo, como mostra a equação 1 :

$$
\% \text { RENDIMENTO }=\frac{\text { Brix inicial }- \text { Brix final }}{\text { Brix inicial }} \times 100
$$

A escala de Brix foi utilizada para determinar a concentração de açúcar no meio fermentativo, aplicando o método de refratometria, utilizando refratômetro portátil para a leitura, efetuando a devida correção de temperatura.

Com o objetivo de otimizar os rendimento do processo de bioetanol e assim aprimorar as metodologias analíticas, um planejamento experimental $2^{3}$ completo foi realizado verificando dentre as variáveis e níveis estudados os parâmetros relevantes. As amostras foram realizadas em duplicata, e as variáveis estudadas apresentando seus respectivos máximos e mínimos, conforme a Tabela 1. 
Tabela 1: variáveis do planejamento experimental $2^{3}$

\begin{tabular}{lccc}
\hline & Fatores & $(-)$ & $(+)$ \\
\hline 1: Fermento $(\mathrm{g})$ & & 0,2 & 1,0 \\
2: Ácido Acético $(\%)$ & 1,0 & 5,0 \\
3: Furfural $(\mathrm{g} / \mathrm{L})$ & & 1,0 & 4,0 \\
\hline
\end{tabular}

\section{RESULTADOS E DISCUSSÕES}

A matriz de planejamento foi montada conforme a Tabela 2, com base no planejamento experimental $2^{3}$ completo. A resposta obtida é em rendimento a partir do Brix, com o Brix inicial 8,0 medido sem a presença de nenhum dos parâmetros.

Tabela 2: Matriz de planejamento fatorial $2^{3}$

\begin{tabular}{cccccc}
\hline Ensaio & $\mathbf{1}$ & $\mathbf{2}$ & $\mathbf{3}$ & Rendimento (\%) & Média \\
\hline 1 & - & - & - & 30 & 30 \\
2 & + & - & - & 40 & 45 \\
3 & - & + & - & 17,5 & 15 \\
4 & + & + & - & 12,5 & 12,5 \\
5 & - & - & + & 22,5 & 22,5 \\
6 & + & - & + & 30 & 30 \\
7 & - & + & + & 12,5 & 10 \\
8 & + & + & + & 5 & 0 \\
\hline
\end{tabular}

Com os resultados apresentados pode-se observar que o maior rendimento reacional foi no ensaio 2, onde se encontram os maiores níveis de fermento e os menores níveis de inibidores.

Em posse dos resultados foi possível determinar os efeitos principais e de interação para o planejamento realizado, a Tabela 3 mostra os resultados para os efeitos e os seus respectivos erros padrões.

Tabela 3: Efeitos e combinação linear das interações

\begin{tabular}{c|cc}
\hline Media Global & $20,94 \pm 0,49$ & Significativo \\
\hline Efeitos Principais & & \\
\hline 1 (Fermento) & $1,88 \pm 0,99$ & Não Significativo \\
$\mathbf{2}$ (Ácido Acético) & $-20,62 \pm 0,99$ & Significativo \\
$\mathbf{3}$ (Furfural) & $-8,75 \pm 0,99$ & Significativo \\
\hline Efeitos de Interação & & Significativo \\
\hline $\mathbf{1 2}$ & $-8,12 \pm 0,99$ & Significativo \\
$\mathbf{1 3}$ & $-2,5 \pm 0,99$ & Não Significativo \\
\hline $\mathbf{2 3}$ & $1,25 \pm 0,99$ & \\
\hline Efeitos de Interação & & Não Significativo \\
\hline $\mathbf{1 2 3}$ & $0,0 \pm, 099$ &
\end{tabular}


No tratamento dos resultados, foram utilizadas equações de cálculo dos parâmetros estatísticos com base em Bruns et al. (2007). O modelo estatístico usado para descrever as respostas do planejamento foi formulado em termos dos efeitos por unidade de variação dos fatores.

$$
y\left(x_{1}, x_{2}, x_{3}\right)=20,94-10,31 x_{2}-4,38 x_{3}-4,06 x_{1} x_{2}-1,25 x_{1} x_{3}
$$

Foi possível observar que o aumento da concentração de ácido acético causou uma diminuição no rendimento reacional, o mesmo acontece com o furfural. Isso acontece porque segundo Freitas (2011), a adição de concentrações crescentes de ácido acético afeta o crescimento da levedura, provocando um aumento da duração da fase de latência e da fase exponencial, com redução do valor da taxa especifica de crescimento. No caso do furfural, Taherzadh et al. (2007) relata que o crescimento de $S$. cerevisiae em meio sintético é inibido em $89 \%$ quando em presença de $4 \mathrm{~g} / \mathrm{L}$ de furfural, comprovando assim o efeito da diminuição do rendimento a medida que avaliamos os níveis máximos.

Já nos efeitos de interação entre ambos não se faz significativa no rendimento, na faixa estudada. Para a verificação da modelagem, é necessário adequá-lo a um modelo linear, quadrático ou até mesmo cúbico. Iniciando, pelo teste do modelo linear, onde se faz necessário a análise de variância (ANOVA), como mostra a Tabela 4.

Tabela 4: Análise de Variância (ANOVA)

\begin{tabular}{lccc}
\hline \multicolumn{1}{c}{ Fonte de variação } & Soma quadrática & $\mathbf{N}^{\circ}$ de g. $\mathbf{~ I . ~}$ & Média Quadrática \\
\hline Regressão & $2.296,88$ & 4 & 574,22 \\
Resíduos & 51,56 & 11 & 4,69 \\
Falta de Ajuste & 20,31 & 3 & 6,77 \\
Erro puro & 31,25 & 8 & 3,91 \\
Total & $2.400,00$ & 15 & \\
\hline
\end{tabular}

$\%$ de variação explicada: $96 \%$

$\%$ máxima de variação explicável: $99 \%$

Segundo Box et al. (1973), o teste $\mathrm{F}$ foi realizado onde se leva em conta os graus de liberdade apropriados, o mesmo é utilizado para realizar previsões no sentido da significância da equação obtida. A razão entre a média quadrática da regressão e a do resíduo deve ser maior que o ponto de distribuição $\mathrm{F}$ para que se tenha um maior grau de confiabilidade, se possível, dez vezes maior. Assim, MQR/MQr = 122,43> (10 x F4,11); F4,11 = 3,36 (para 95\% de confiança), mostra que temos um ajuste altamente significativo. A Figura 1, nos mostra o ajuste realizado ao modelo linear, assim como os valores mostrados na ANOVA. 


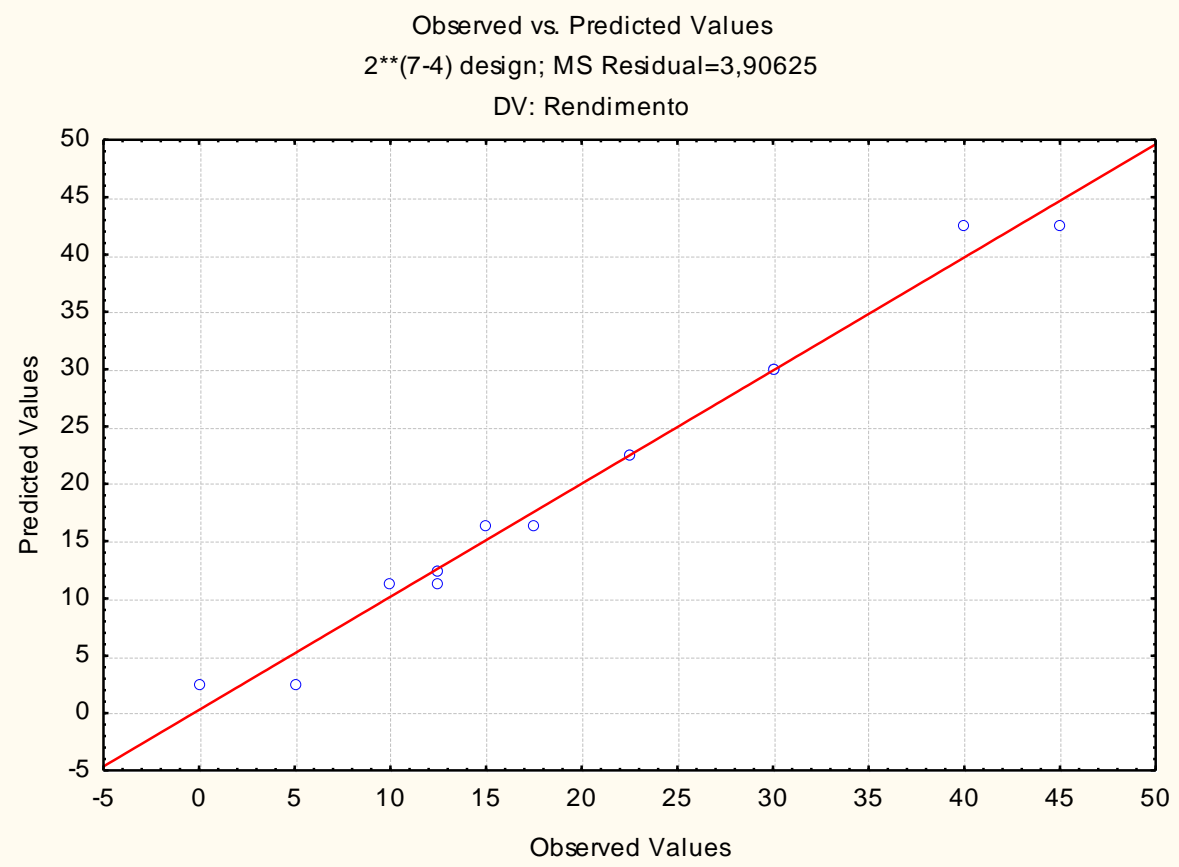

Figura 1: Ajuste ao Modelo Linear.

A superfície de resposta foi gerada para o modelo linear, apresentada na Figura 2, que se adequou ao sistema, sendo desnecessária a busca por outro modelo.

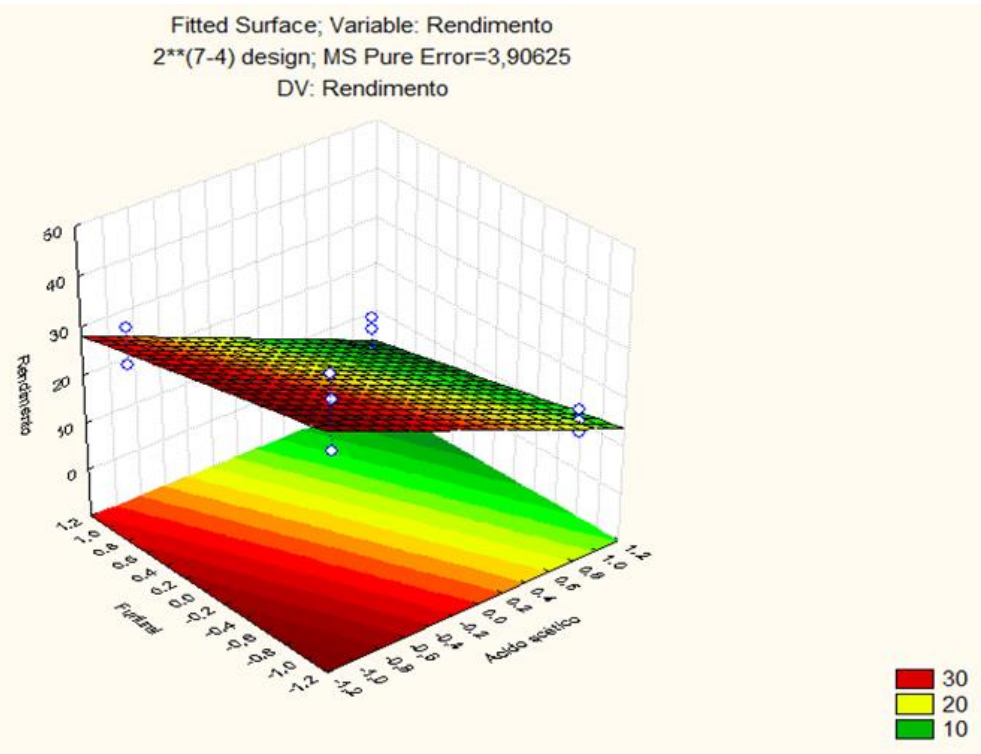

Figura 2: Superfície de Resposta.

Através da superfície de resposta confirmamos o que foi apresentado, à medida que os fatores significativos, ácido acético e furfural, variam de um nível maior para um nível menor 


\section{9 a 22 de outubro de 2014 \\ Florianópolis/SC}

observamos um aumento significativo no rendimento reacional.

De acordo com Talcott et al. (1999), à presença destes compostos tóxicos, quando o hidrolisado hemicelulósico é utilizado diretamente em processos de bioconversão, sem serem submetidos a um tratamento prévio de destoxificação, ocorre diminuição na eficiência do processo fermentativo que atinge baixo rendimento e produtividade. Logo, o resultado obtido é totalmente aceitável uma vez que diminuiu o rendimento reacional à medida que se atingia as maiores concentrações desses inibidores.

\section{CONCLUSÃO}

Os resultados experimentais obtidos neste trabalho permitem concluir que o rendimento reacional aumenta à medida que se diminuí a concentração dos inibidores, dentre os estudados, ácido acético e furfural avaliados como efeito principal. Quando se analisa sua interação, não há um efeito significativo dentro da faixa avaliada. A quantidade de fermento estudada como parâmetro principal não oferece alteração ao rendimento da reação. Os maiores rendimentos foram obtidos no ponto de máximo de fermento $(1,0 \mathrm{~g})$, mínimo de ácido acético $(1,0 \%)$ e mínimo de furfural $(1,0 \mathrm{~g} / \mathrm{L}) \mathrm{com}$ média de $42,5 \%$.

Os estudos sobre os efeitos e das combinações lineares do planejamento fatorial $2^{3}$, apresentou uma estimativa do aumento do rendimento à medida que se diminuía 20,62\% de ácido acético, da mesma forma com a diminuição 8,75\% de furfural. Já nos efeitos interativos, de ácido acético e furfural assim como fermento, ácido acético e furfural, os valores obtidos na base de cálculo não geraram significância como interferência no rendimento, isso dentro dos pontos máximos e mínimos estudados. O estudo realizado ressalta a necessidade de uma etapa de destoxificação, para o material lignocelulósico, visto que a presença desses inibidores causa uma baixa na produtividade.

\section{REFERENCIAS}

BOX, G. E. P.; WETZ, J. Criteria for judging adequacy of estimation by an approximate response function. University of Wisconsin Technical Report 9, 1973;

BRUNS, R. E.; NETO, B. B.; SCARMINIO, I. S.. Como Fazer Experimentos - Pesquisa e Desenvolvimento na Ciência e na Indústria. Editora Unicamp, $3^{\circ}$ edição, 2007.

FREITAS, C. S. S. Utilização da citometris de fluxo multiparamétrica na monitorização da resposta fisiológica da levedura Saccharomyces carlsbergensis em presença de ácido acético na produção de bioetanol. 76p. Dissertação de mestrado - Departamento de Engenharia de Sistemas Bioenergéticos, Universidade Técnica de Lisboa, Lisboa, 2011.

MOSIER, N.; WYMAN, C.; DALE, B.; ELANDER, R.; LEE, Y.Y.; HOLTZAPPLE, M.; LADISCH, M. Features of promising technologies for pretreatment of lignocellulosic biomass. Bio. Tech., v.96, p.673-686, 2005.

PEREIRA Jr., N. Biomassas residuais de composição lignocelulósica para a produção de etanol e o contexto de refinaria, 2007.

Renewable Fuels Association. Etanol industry statistics, 2010. Disponível em: 
http://www.ethanolrfa.org/pages/statistics.

SANTOS, M. S. R. Estudo de pré-tratamento de palha e sabugo de milho - visando a produção de etanol de 2G. 77p. Dissertação de mestrado - Departamento de Engenharia Química, Universidade Federal de Alagoas, Maceió, 2014.

TAHERZADEH, M. J.; KARIMI, K. Acid-based hydrolysis processes for etanol from lignocellulosic materials: a review. Bio. Resources, Vol 2, 472-499. (2007).

TALCOTT, S.T.; HOWARD, L.R. Phenolic Autoxidationis Responsible for Color Degradation in Processed Carrot Puree. Journal of Agricultural Food Chemistry, v.47, p.2109-2115, 1999.

WOLF, L. D. Pré-tratamento organossolve do bagaço de cana-de-açúcar para a produção de etanol e obtenção de xilooligômeros. 147p Dissertação (Mestrado em Engenharia Química na Área de Pesquisa e Desenvolvimento de Processos Químicos) - Universidade Federal de São Carlos, São Paulo, 2011.

ZHANG, Y.; WANG, L.; CHEN, H. Formation kinetics of potential fermentation inhibitors in a steam explosion process of corn straw. Applied Bioch. Biotechnol, v. 169, p. 359-367, 2013.

ZHAO, X.-Q.; ZI, L.-H.; B., F.-W.; L., H.-L.; H., X.-M.; Y., G.-J.; HO, N. W. Y. Bioethanol from lignocellulosic biomass. Adv. Bioch. Engin/Biotechnol, 2011. 